\title{
Tasmania's Tamar Valley Pulp Mill: A Comparison of Planning Processes Using a Good Environmental Governance Framework
}

\section{Introduction}

Liberal democracy is not delivering good environmental results. From climate change to watershed destruction, from habitat loss to fisheries depletion, outcomes at the local, national and global levels leave a great deal to be desired. The upshot is that needed policies are watered down and then delayed by powerful, negatively affected 'old economy' interests appealing to 'environmental realism'. Nature, paying no heed to such self-regarding actions and the spin used to justify them, continues to react in complex and chaotic ways to the cumulative effects of unsustainable production. The results are well known: a thinning of the ozone layer, a warming the earth, deforestation, soil erosion, desertification and species extinction.

The difficulty is that the institutions that have evolved to make liberal democracy work exert insufficient control over powerful actors-business and governmentsbetween elections. While mainstream political parties are adept at using the rhetoric of sustainable development, in practice the policies they formulate are tailored to deliver benefits to core constituencies. Thus, once in government, party leaders of whatever hue support rapid economic development to deliver jobs, profits and taxes. The broader environmental and community costs associated with the projects and programs designed to achieve these outcomes are downplayed or, at times, completely ignored.

This driving need of mainstream political parties to support economic development despite potentially high environmental and community costs is no where more clearly illustrated than in the recent conflict in Tasmania over a proposal to site a pulp mill at Long Reach, near Bell Bay, on the banks of the Tamar Estuary. Endorsed by the Australian Labor Party (ALP) and the Liberal Party of Australia at both state and Commonwealth levels, the pulp mill proposal has been assessed locally under two different processes. The initial assessment, undertaken by the state's planning body, the Resource Planning and Development Commission (RPDC), was aborted when the proponent, Gunns Ltd, pulled out in March 2007. In response, the state government rushed the Pulp Mill Assessment Act (PMAA) through parliament to deliver an alternative, 'fast-track' assessment, an arrangement fully endorsed by the state Liberal Party. Notwithstanding bipartisan support from Tasmania's political economic elites, opinion polls have consistently indicated that neither the pulp mill nor the process used to approve it have the support of the majority of Tasmanians.

This article assesses the Tamar Valley pulp mill case from a 'good environmental governance' perspective. The article is divided into four sections. Following this introduction, an account of Gunns' decision to pull out of the RPDC process is presented along with the government's decision to fast track an assessment through the PMAA. In Section three, a comparison of the RPDC and PMAA processes is conducted using a good environmental governance framework composed of eight elements - transparency, openness, balance, accountability, deliberation, efficiency, science and risk. The comparison reveals that the PMAA process was seriously deficient across six of the eight criteria. In the final concluding section, the significance of the Tamar Valley pulp mill case for project planning in liberal democracies is assessed, with calls for more and better intermediary institutions 
endorsed to secure not only 'rule by the people' but also better outcomes for the environment and the communities that depend on them.

\section{The Tamar Valley Pulp Mill Case}

The story commenced in mid-2003 with rumours that Gunns Limited, a major Tasmanian forest products company, wanted to build a pulp mill in the State to add value to its woodchip exports (ABC 2007c). Following a request from Labor Premier Paul Lennon, the State's planning body (the Regional Planning and Development Commission, RPDC) drew up a set of 'best practice' guidelines. ${ }^{1}$ The Guidelines, released for public consultation in June 2004, were approved in October. Shortly thereafter Gunns requested the Premier to declare its proposed pulp mill a 'Project of State Significance', Tasmanian planning-speak for it to be assessed by the RPDC.

\section{Long Reach or Hampshire?}

Gunns' first task was to determine where to site the mill and two locations in Northern Tasmania were considered: Long Reach near Bell Bay on the Tamar Estuary and Hampshire, south of Burnie. In February 2005, the company announced Long Reach on the Tamar Estuary as its preferred site, justifying its selection almost exclusively on economic grounds related to cost savings from (i) proximity to plantation feedstock, (ii) an established deep sea port, and (iii) ready supplies of electricity and gas. The reduced requirement for road transportation was cited as an important social and environmental benefit. Detailed comparative cost estimates of both sites do not appear to have been publicly released, but the consultant who undertook the feasibility study reported savings of \$24 million per annum for the Long Reach site in transportation costs alone (Sunday Examiner 2005). ${ }^{2}$

In June 2005, Gunns submitted a detailed proposal to the RPDC. To this point, most Tasmanians, including the ALP Government, appeared satisfied with the process. Premier Lennon was quoted as saying he had full confidence in the RPDC: 'They've demonstrated that they're capable of doing this appropriately, bad projects get thrown out by the RPDC' (ABC News 2005a). Despite popular satisfaction, however, Gunns' executive chairman, John Gay, warned Tasmanians the same month that the investment was not guaranteed and the company could build the mill elsewhere (ABC News 2005b). His comment was repeated in the run up to the March 2006 Tasmanian State election, when Gunns stated it might have to move the project to China if a hung parliament were voted in (ABC News 2006a). ${ }^{3}$

The pulp mill was not yet a major political issue. Les Rochester, the spokesperson for the Tamar Residents Action Committee (TRAC), which had formed shortly after Gunns announced it was considering building a mill, stood for election in the seat of Bass and received just over 1100 votes, well short of a quota under Tasmania's HareClark proportional representation system. Overall, there was only a small swing away from the ALP in the 2006 state election and no change in the parties' standing in Parliament. Labor retained its lower house majority, winning 14 of the 25 seats in the Legislative Assembly, with the Liberals and Greens trailing with 7 and 4 seats respectively. ${ }^{4}$

\section{Things Fall Apart}

It was shortly after the March 2006 election that the pulp mill assessment process began to unravel from the perspective of Gunns and the ALP Government. For Gunns, 
costs associated with the RPDC assessment process were becoming a concern. In July, the company's pulp mill project manager announced that it had spent \$11 million preparing its Integrated Impact Statement (IIS), and expected to pay out over $\$ 40$ million before final approval. The company was under some financial pressure in international markets, reportedly losing market-share to mainland competitors as Japanese buyers began to express a preference for plantation woodchips over woodchips from native forests (ABC News 2006b). ${ }^{5}$ Gunns' share price trended down from \$3.30 at the end of March to a low of \$2.56 at the end of September before staging a modest recovery. ${ }^{6}$

Gunns' IIS was also coming under sustained scrutiny. Reports commissioned by the RPDC as well as stakeholder submissions from groups such as the Tasmanian Council on Social Services, the Royal Automobile Club of Tasmania, the Tasmanian Fishing Industry Council, Investors for the Future of Tasmania and the Dorset Council raised a range of concerns about the mill's economic, environmental and social impacts. Specific issues identifed related to the mill's net economic costs and benefits, the adequacy of wood supplies and transportation networks, the composition and volume of air, land and water emissions, workforce arrangements and odour. In advance of the RPDC's October Directions Hearing, then-Executive Commissioner Julian Green requested supplementary information from Gunns on many of these matters.

Gunns appeared nettled by these new requests for information and continued to demand a speedy conclusion to the RPDC assessment process. This demand could not be met, however, due to allegations of government interference that surfaced in late 2006. This interference was alleged to originate from the government's own Pulp Mill Task Force (PMTF), a promotional body set up by the government to spruik the mill's benefits. From its website to its newsletters to its bus tours, the PMTF advertised the economic advantages of pulp mills in general and the Tamar Valley proposal in particular. The activities of the Task Force were a serious concern to Green, who continuously sought the Premier's assistance to rein it in, apparently with little effect (Neales 2007a).

Green was determined that there should be no factual basis for an allegation of actual or 'apprehended bias' against any of his commissioners that might warrant their removal. However, in late October, the Tasmanian Greens made just such an allegation against Warwick Raverty, the CSIRO pulp mill expert on the panel, on the basis that he was an employee of Ensis, a company that had 'already formed a clear view with respect to the Pulp Mill Project in general terms, and in respect of some of the crucial issues' (Sealy 2006). Once the allegation was made, it was critical that no prima facie evidence exist to substantiate it, but the PMTF had employed CSIRO information concerning pulp mills on its website, and even signed a contract with Ensis, a CSIRO affiliate, to conduct a study of bleached pine toxicity. While the RPDC received legal advice that there was no truth to the allegation, fighting it through the courts would take time-according to Raverty upwards of two years. ${ }^{7}$ Raverty felt obliged to tender his resignation and Green felt he had no option but to accept it and tendered his own shortly afterwards, prompting the first RPDC crisis in early January 2007 (ABC News 2007a). 


\section{Wright Action}

With the resignations of Raverty and Green, the RPDC assessment process was in disarray. The Premier needed to act decisively to restore public confidence. This he did by appointing an eminent, retired Supreme Court Judge, Christopher Wright, to chair the pulp mill assessment panel. In making the appointment, the Premier stated that: 'Mr Wright is ideally suited to oversee the pulp mill assessment process and is held in high esteem not only in legal circles but right across the Tasmanian community' (Price 2007). The Premier's high opinion of Wright lasted barely a month, however. By late February, he appeared frustrated by the former judge's unwillingness to tailor the RPDC assessment process to Gunns' firmly stated deadline of June $30^{\text {th }}$. Gunns, too, was increasingly alarmed, not only because the new panel chair appeared to blame the company at a Directions Hearing in Launceston on 22 February for past delays, but also because of the RPDC's evident dissatisfaction with with the company's IIS and Supplmentary Information. ${ }^{8}$ This was the context in which, following the Launceston Directions Hearing on 22 February 2007, the Premier met with Gunns' Executive Chairman John Gay to discuss options and, following that meeting, with Christopher Wright in a bid to speed the RPDC process up.

While the Premier appears to have viewed the meeting as an exploration of options, Wright considered it an inappropriate attempt to pressure him to hasten and weaken the RPDC process to meet Gunns’ preferred timeline (Herr 2007). On March 2 Wright tendered his verbal resignation to Linda Hornsey, Secretary of Premier \& Cabinet, and later drafted a letter of resignation. Wright claims the letter was not sent because Hornsey contacted the Premier who issued assurances that he did not intend to legislate a fast-track process (Stedman 2007a). But things were going from bad to worse. On March 9, the acting Executive Commissioner of the RPDC, Simon Cooper, who had taken over in that capacity following Julian Green's resignation, sent a letter to Hornsey outlining deficiencies in the supplementary information submitted by Gunns and concluding that the proposal was in 'critical non-compliance' with its requirements. Hornsey requested the letter not be sent, and is reported to have informed Gunns of its contents on 8 March (Neales 2007c). Shortly afterwards, on 14 March, Gunns announced to the Australian Stock Exchange that it was withdrawing from the RPDC process (Denholm 2007).

\section{Quitting the RPDC}

Why did Gunns pull out of the RPDC process? Officially the company cited 'the lack of certainty over when a final decision will be delivered' which had 'placed the company in an untenable position and imposed a significant impact on the financial risk of the project' (Gunns 2007). While this argument has face validity, the justification needs to be qualified in three major respects. Firstly, the market pressure Gunns was under put a premium on an early start date for mill construction and it had already entered into contract arrangements with several companies-Poyry, Andritz, John Holland and MacMahon Contractors - for the design and construction of the mill post-September 2007. These contracts, plus lost earnings, enabled the company to claim that the cost of delay post-September would be more than a million dollars per day (Neales 2007d). ${ }^{9}$

The second qualification is that Gunns appears itself to have contributed significantly to the delays it complained about. This was certainly Wright's view, who noted at his 
first Directions Hearing in Launceston in February 2007 that: ' $\ldots$ it has become quite apparent that due to accumulated delays, all or most of which appear to have resulted from Gunns' failure or inability to comply with their own prognostications or the panel's requirements, that time line [completion by May 28 2007] can no longer apply’(Wright 2007, 3). ${ }^{10}$

The third qualification is that by early March Gunns' share price was dropping sharply following a poor mid-term report to the Australian stock exchange (Ellison 2007). In late February, the company's shares were trading at around $\$ 3.10$ but fell to around \$2.62 in early March. ${ }^{11}$ Analysts, it appeared, reacted to the company’s reduced financial performance as well as to increased concerns about whether the pulp mill could be approved under the RPDC process. The remarkable recovery in the company's share price following the announcement that it was pulling out of the RPDC process provides some support for this supposition. Gunns shares spiked after March 14 and traded above $\$ 3.40$ over the next couple of months.

While cost pressures were certainly a key factor in explaining Gunns' decision to pull out of the RPDC process, there is another, additional and very plausible explanation. The company was increasingly worried about its capacity to satisfy the RPDC's commissioners. Not only has it been claimed that the RPDC was trying to get the company to shift the proposed mill to Hampshire (Neales 2007j), but this together with endless bickering between Gunns and the RPDC over the supply of information suggested that the final recommendations of the planning body would be heavily qualified, costly to implement, and commercially unacceptable.

\section{Tri-Polar Pulp Mill Politics}

Despite being rewarded by the financial community for abandoning the RPDC process, Gunns' action was greeted with consternation by many Tasmanians. Most appeared to have been content to allow the RPDC process to take its course and to have been willing to accept the verdict from the 'independent umpire'. Following the demise of the RPDC's inquiry, three positions on the mill emerged. The first, pro-mill position was strongly endorsed by Tasmania's political economic elite, heavily dependent as it is on the forest sector for political party funding and votes. Key players in the pro-mill coalition included both mainstream political parties, the Forest Industry Association of Tasmania (FIAT), the Construction Forestry Mining Energy Union (CFMEU), and Timber Communities Australia (TCA). These actors were backed by a broader coalition of business interests represented by the the Tasmanian Chamber of Commerce and Industry (TCCI) (TCCI 2007). The majority of TCCI members heavily endorsed the pulp mill despite trenchant opposition from a sizeable minority. In addition, several northern municipalities supported the mill including, controversially, Launceston, many of whose rate payers were alarmed about about the mill's potential impact in the region.

In direct opposition stood the anti-mill coalition led by the Tasmanian Greens and The Wilderness Society (TWS) with backing from a diverse group of Tamar residents linked to two newly formed organisations: Tasmanians Against the Pulp Mill (TAP) ${ }^{12}$ and Investors for the Future of Tasmania (IFT). At the outset, the fact that the antimill coalition was led by Tasmania's major environmental groups enabled the promill campaign to brand opposition to the mill as being promoted by 'greenies'. This appellation has proved very effective in Tasmania, evoking strong negative emotions 
from many businesspeople and workers alike. Once IFT entered into the debate, however, a simple 'us' versus 'greenies' dichotomy was more difficult to sustain. IFT was composed of businesspeople, albeit those linked to a 'new economy' model of development, especially those working in 'tourism, food, wine and farming' (Denholm 2007x). This fragmentation along old/new economy lines constituted a new development in Tasmanian politics. Many IFT members were unwilling to reveal their identities initially for fear of reprisals; one notable exception, however, was Graeme Wood, founder of Wotif.Com. IFT played an important role in the anti-pulp mill campaign, running a series of hard-hitting ads in both state newspapers partially offsetting the massive advertising and marketing campaigns launched by the Government, Gunns and the CFMEU. ${ }^{13}$

While the media focused on the stand-off between pro- and anti-mill forces, a third, more inchoate group emerged in early 2007 around the issue of due process and ethics in government. This group included academics at the University of Tasmania, members of the Planning Institute of Australia, members of the clergy and some politicians. While very much more a loose affiliation of individuals than a formalised group, those involved articulated a concern over ethics, due process, deliberation and good governance. Diverse actions were taken including the publication of a letter in The Hobart Mercury by 14 University of Tasmania academics critical of the Government's assessment process (Duncan 2007a) ${ }^{14}$; a press release by the Planning Institute of Australia-Tasmania Division expressing 'considerable concern' over the decision to remove the pulp mill from the RPDC assessment process (Planning Institute of Australia, 2007); and a report prepared by Dr Andrew Corbett, a clergyman of the Legana Christian Church (Assembly of God), entitled 'Christian Response to the Bell Bay Pulp Mill' which highlighted the basic Christian values of integrity, honesty and due diligence that he thought were lacking in the current process (Neales 2007e; Corbett 2007). ${ }^{15}$ These concerns over the process used to approve the pulp mill were further articulated by several parliamentarians including two ALP members, Lisa Singh and Terry Martin, in speeches to the Tasmanian Legislative Council concerning the Pulp Mill Assessment Bill 2007.

\section{Pulp Mill Assessment Act, 2007}

Gunns pulled out of the RPDC process on 14 March 2007 and nine days later Tasmania's House of Assembly passed the Pulp Mill Assessment Bill 2007. The Bill was viewed by many as a hastily drafted and draconian piece of legislation widely rumoured to be Gunns ‘dream bill'. Certainly, the President of Tasmanian's Upper House, Franklin Legislative Council member Don Wing, regarded the involvement of Gunns' lawyers in drawing up the bill as 'unique' (Duncan 2007b). The bill, described by long-time Tasmanian political commentator Richard Herr as 'fatally compromised' because it contained provisions that prevented legal action under criminal law (including corruption), quickly passed Tasmania's Lower House with the support of all 14 ALP and all seven Liberal members, with only the four Greens voting against. All eyes then turned to the 15-seat Legislative Council and the capacity of its members to function as a house of review. ${ }^{16}$

Despite some fireworks associated with the long-anticipated crossing-of-the-floor by disaffected Labor MLC Terry Martin, commentators were mostly disappointed with the Upper House's performance with respect to the Pulp Mill Assessment Bill. While amendments were made to Section 11 to ensure that legal action was permissible in 
the event of criminal activity, the Bill survived largely intact through the committee process. Commentators present highlighted a number of unusual procedures. Upper House members were placed under extraordinary pressure by the Government to pass the legislation, assisted by a Gunns' lobbyist, Tony Fletcher, a former Legislative Assembly parliamentarian with more than 14 years' experience. According to one parliamentary observer, 'With his familiarity in, and open access to, the corridors of power, Mr Fletcher also assumed a role normally taken by the State Government, negotiating individually with independent MLCs to drop or tone-down troublesome amendments that either did not suit the Government—and presumably Gunns—or might have slowed the tight approval timetable' (Neales 2007g). ${ }^{17}$

Despite the objections of a minority of MLCs ${ }^{18}$ the final vote on the Pulp Mill Assessment Bill 2007 was nine in favour and five against. ${ }^{19}$ The bill, with minor amendments that the Government had already agreed, was then sent back to the Lower House, where it was passed a couple of weeks later. The new assessment process was now enacted in legislation under the Pulp Mill Assessment Act 2007 (hereafter PMAA or the Act) and the Government moved immediately to implement it. The process set out in the Act provided for the Government to hire a consultant to assess the degree to which the proposed mill met the RPDC emissions guidelines. ${ }^{20}$ While commentators viewed BECA Amec, a company that had been advising the RPDC, as best placed to carry out the consultancy, in fact it decided not to enter a bid. Its Australian representative, John Wall, is quoted as saying 'the company could only provide technical advice and not a recommendation whether the mill should or shouldn't proceed' (Stedman 2007b). Instead, following a competitive tender, the Government chose a little-known Scandinavian company, Sweco Pic, to carry out the task. It also commissioned ITS Global to conduct a study on the pulp mill's economic and social benefits and both reports were released to the public on 5 July 2007.

Sweco Pic's report assessed a convenient 100 emissions aspects of the project, concluding that 92 of them met the RPDC Guidelines. Of the 8 outstanding, two were viewed as insignificant and the report recommended that the remaining six be dealt with through the permitting and licensing system for the pulp mill. In the conclusion to its Executive Summary, the Report recommended that 'the project can proceed to further consideration by the Tasmanian Parliament' on the assumption that 'the matters recommended in this report will be addressed in any permit conditions prepared for the Parliament by the Minister of Planning...' (Sweco Pic 2007). The ITS Global Report endorsed the project's economic and social benefits, noting that 'the numbers demonstrate the gains to Tasmania of the Pulp Mill', that failure to proceed would 'discourage other large investors', and that 'the either/or dichotomy [between industrial production and tourism] promoted by anti-pulp mill forces is false' because 'there is no economic or social basis for the 'either/or' contention' (ITS Global 2007).

The Tasmanian government immediately accepted the two consultants' reports and returned to parliament where the mill was finally approved in late August with overwhelming support in both houses. At this point, however, further delays occurred as federal Environment Minister Malcolm Turnbull, under environmental pressure in his own electorate of Wentworth and with a federal election pending, decided first to extend and deepen the commonwealth review process by having the Chief Scientist, Jim Peacock, conduct a review of the mill's proposal. Peacock spent September 2007 
conducting the review and it was only in early October, therefore, that the Gunns' pulp mill was finally approved by both levels of government, with the Commonwealth government imposing a total of 48 conditions on its operation (Hobart Mercury 2007a). The ensuing Commonwealth election led to extensive publicity concerning the pulp mill across Australia, with efforts made to unseat high profile incumbents including Turnbull and Peter Garret, the shadow environmental minister. The political fall out from the pulp mill approval is considered further in the conclusion. Before that, however, it is important to subject the two major approval processes used in Tasmania, the RPDC and PMAA, to a thoroughgoing evaluation from a good environmental governance perspective.

\section{Good Environmental Governance}

The concept of 'governance' is ubiquitous today in the world of business, international relations, public administration and political science. Sometimes the word is used as little more than a synonym for 'government' as a form of hierarchical, authoritative command. Used in this way it adds little to our understanding of social phenomena. However, many analysts view governance as referring to the broader task of 'steering and coordinating the affairs of interdependent social actors based on institutionalised rule systems' (Benz quoted in Treib, Bähr and Falkner 2005, 5; see also Tollefson, Gale and Haley, In Press). When preceded by the adjective 'good', the concept takes on an evaluative dimension, most famously by multilateral financial institutions such as the International Monetary Fund (IMF) and World Bank to determine which developing countries qualify for debt relief and aid. The World Bank defines good governance as:

... the traditions and institutions by which authority in a country is exercised for the common good. This includes (i) the process by which those in authority are selected, monitored and replaced, (ii) the capacity of the government to effectively manage its resources and implement sound policies, and (iii) the respect of citizens and the state for the institutions that govern economic and social interactions among them (World Bank 2007).

The World Bank's ‘thin' conception of 'good governance' has been criticised by many as a trojan horse for liberal democracy (i.e., Kirby 2004). From the World Bank's perspective, Tasmania is already an example of 'good governance' because the citizens vote in competitive, 'free' and 'fair' elections; there is capacity to effectively manage resources and implement policies; and, notwithstanding present dissatisfaction, its citizens broadly respect the institutions of government even thought they clearly disagree with specific outcomes. While it would be churlish to deny that good governance as defined by the World Bank is desperately needed in many Third World countries, a thicker conception of the concept is required in a developed country context where an informed, literate and engaged citizenry demonstrate the capacity and the desire to participate in decision making processes.

Such a thick conception of good governance has been developed by a number of scholars including the Institute on Governance (IOG), a Canadian NGO. IOG considers good governance to be

about more than getting the job done. Especially in non-profits, government agencies and the like, where values typically play an important role in 
determining both organizational purpose and style of operation, process is as important as product. Good governance becomes more than only a means to organizational effectiveness and becomes an end in itself (Institute on Governance 2007).

In elaborating on the importance of the good governance process, the IOG identifies the following key features: participation, transparency, responsiveness, consensus orientation, effectiveness and efficiency, accountability and strategic vision. The IOG list shares similarities with lists compiled by other analysts. For example, the Global Accountability Framework uses transparency, participation, evaluation and complaint mechanisms as the key criteria in pursuit of its mission of making global governance more accountable (One World Trust 2007); and Lockwood et al (forthcoming) identify legitimacy, transparency, accountability, inclusiveness, fairness, integration, capability and adaptability.

While there is no definitive conception of good environmental governance as yet, it can be elaborated by building on the IOG, One World Trust, Lockwood et al and wider governance approaches (Rhodes 1996 and 1997; Tollefson 1998; Pierre 2000; Kooiman 2002; Kjaer 2004; Cashore, Auld \& Newsom 2004; Treib, Bähr \& Falkner 2005; Rhodes 2007; Tollefson, Gale and Haley In Press) but tailored specifically for environmental decision making. Based on this literature, good environmental governance is defined here as a set of transparent, accountable, open, balanced, deliberative, efficient, science-based and risk-based processes for steering and coordinating the affairs of interdependent social actors in the making of environmental decisions. To illustrate more precisely the analytic utility of this concept, a comparison of the RPDC assessment process for Gunns' proposed pulp mill with the PMAA process that replaced it is conducted in the remainder of this section.

\section{Transparent Decision Making}

Transparency has been defined as: "the provision of accessible and timely information to stakeholders and the opening up of organisational procedures, structures, and processes to their assessments” (Lloyd, Oatham \& Hammer 2007). All things being equal, a better decision will emerge when the 'facts' are to hand. ${ }^{21}$ It is now well documented that the first major conflict of the twenty-first century was launched on the basis of misinformation about weapons of mass destruction perpetrated by antiBaathist agents and readily disseminated by the US and British governments intent on achieving their own strategic objectives. Leaders in both countries deliberately distorted and 'sexed up' available intelligence data to create a far stronger case for war than actually existed (Pillar 2006).22 Information, in short, is a strategic resource, and proponents and opponents of a policy or project have strong incentives to use it as such. The RPDC assessment fostered transparency by acting as an independent filter, tester and publiciser of high-quality information. Operating at arms' length from pressure groups and the Tasmanian Government, and with its own budget to fund consultancies, the RPDC was able to review the claims and counter-claims of proponents and opponents alike. In contrast, under the PMAA, the Government took back control over the flow of information through the consultancy process. The government established the terms of reference for these consultancies, recruited and paid Sweco Pic and ITS Global, and scrutinised drafts of their reports prior to final release. Opportunities to test the claims and counter-claims of these experts were 
eliminated, replaced by a $\$ 300,000$ advertising campaign to market the mill to an increasingly sceptical public (Duncan 2007c).

\section{Accountable Decision Making}

A straightforward, if traditional, definition of accountability is 'the obligation to answer for a responsibility conferred' (Barrados 2003). ${ }^{23}$ This definition highlights the 'vertical' dimension of accountability upwards and downwards based on a principle of delegation. Thus, if care of the elderly is devolved to the private sector via forms of contracting out, nursing homes become 'accountable' to the health department for the care provided, which must conform to the provisions of their licenses. If nursing homes are negligent then penalties can be invoked by the department; if the department is negligent (and, say, tries to cover up cases of abuse), then under the Westminster model, the minister of health is deemed accountable and should resign, taking 'ministerial responsibility' for the policy implementation failure.

While useful, the conventional definition of accountability needs to be supplemented by one that emphasises responsibility to actors other than those with formal delegated authority. In this 'horizontal' conception of accountability, actors are responsible to a much wider range of actors based on the 'all affected' principle, with more powerful actors being concomitantly more accountable. ${ }^{24}$ Keohane, who considers this a form of 'external accountability', defines it as occurring when 'organizations are held accountable not to those who delegated power to them, but to those who are affected by their actions' (Keohane 2006, 79). Importantly, Keohane observes that accountability is itself a power relation, and one that actors are unlikely to impose on themselves in the absence of external pressure. Building on this insight, KoenigArchibugi (2004) identifies four 'accountability gaps' with respect to multinational corporations related to collusion, regulatory competition, state weakness and political subversion.

Using these two concepts of vertical and horizontal accountability, how does the RPDC assessment process for Gunns pulp mill compare with the PMAA process? Before answering this question, we need to determine who should be accountable to whom. Should it be Gunns, the Government, the Greens, the RPDC, or all those involved? The view taken here is that it should be all of the actors involved, since all have responsibilities with respect to those affected by their decisions. But based on the fact that accountability is a power relationship and that those with more power have concomitantly more responsibility and accountability, the focus here is on the two most powerful actors: Gunns Ltd and the ALP Government. Under the original process, the Government delegated responsibility to the RPDC to assess Gunns' proposal and the RPDC was able to hold Gunns to account for its proposal through a variety of formal mechanisms including the requirement to submit an Integrated Impact Statement, respond to public submissions, produce supplementary information, and address comments made in directions hearings. ${ }^{25}$ Horizontal accountability to other actors, especially those most affected including environmentalists, tourism operators, wine producers, fishers and affected communities in the Tamar Valley, was achieved in part via the use of public submissions and public hearings, where civil society actors had an opportunity to state their case and critically evaluate the evidence presented. 
In contrast, under the PMAA process, Gunns became accountable directly to the Government. Since both the Government and Gunns were enthusiastic supporters of the pulp mill, this vertical accountability relationship actually placed very few burdens on Gunns. Indeed, at times the accountability relation appeared to reverse itself, with the Government holding itself accountable to Gunns for its actions. ${ }^{26}$ But it was the elimination of horizontal accountability that was PMAA's most pernicious feature. Sweco Pic and IIS Global reported directly to the Tasmanian Government and were not required to consult or take account of other affected interests. This, coupled with the elimination of written submissions and public hearings, effectively eliminated horizontal accountability under the PMAA process.

\section{Open and Balanced Decision Making}

While it is popular to regard public policy as the exclusive domain of ministers and bureaucrats, studies of the policy process emphasise the importance of policy networks: interlinked associations of public, corporate and civil society actors that reach consensus on goals, institutions and instruments (Rhodes 1996; 1997). The good governance literature stresses that these networks be open and balanced if fair and balanced public policy is to result (Van Waarden 1992; Tollefson, Gale \& Haley In Press). Openness refers to the degree to which a policy network can accept and accommodate new interests; balance refers to a relative equality of power in decision making. Public policy networks can vary along the dimensions of openness and balance. At one extreme are closed, corporatist policy networks where specific interests, frequently business and labour, exclude all other interests. At the other extreme are relatively open policy networks that adapt themselves to changing social circumstances. Closed policy networks operate in the interests of network members, securing policy decisions that reflect their interests, not necessarily those of the wider public. ${ }^{27}$ Yet, even when policy networks are opened up to include previously excluded interests, decisions will still reflect the interests of dominant actors unless rules are agreed to balance the parties' relative power.

The RPDC offset and balanced to some extent the power of Tasmania's closed forest policy network. It did this by giving voice to other interests, notably those raising issues about the mill's potential negative environmental, community, fisheries, health, tourism and viticulture impacts. Via the RPDC process, these excluded interests had a forum to make their views known via public submissions and hearings. The power of the forest lobby was also offset by the RPDC's ability to hire consultants to review the quality of the original and supplementary information provided. In contrast, the PMAA process re-established the ascendancy of the forest lobby in the public policy decision making process. It did so by narrowing the range of matters to be assessed largely to the pulp mill's emissions of particulate matter and effluent and by putting a forest consultancy company, Sweco Pic, in charge of deciding whether the mill met the original rather than the revised RPDC guidelines. ${ }^{28}$

\section{Deliberative Decision Making}

Deliberation is an important feature of good policy making, particularly in complex and chaotic contexts where the nature of causal relations is unclear and where there is evident social capacity via widespread literacy and informed understanding (see Dryzek 2000; Warren 2002). Deliberation requires the establishment of forums where the claims and counter-claims of protagonists can be considered, assessed and adjudicated. Appropriately structured, deliberation can result in 'social learning'-a 
process whereby the preferences of participants are transformed as they listen to and understand the concerns, rationales and ideas of others (Niemeyer 2004). The RPDC constituted itself as a deliberative forum for the assessment of the claims and counterclaims of the forest lobby and environmentalists. With the resignation of Raverty and Green, however, the RPDC became embroiled in the polarised politics it was responsible for mediating. In appointing Christopher Wright, however, the Government placed the RPDC back on track to complete its work.

Serious deliberation of a project proposal-particularly one as massive and complex as Gunns' proposed pulp mill—must be expected to take time. It is not a decision that can or should be rushed. Wright, on behalf of the RPDC Commissioners, made this clear to the Premier in late February when he came under pressure to meet Gunns' stated deadline of June $30^{\text {th }}$. By then, however, Gunns had had enough. From its perspective, the deliberative process needed to end sooner rather than later and, with Wright refusing to curtail the deliberative process to meet the company's commercially mandated deadline, Gunns felt it had no option but to pull out of the RPDC process.

The PMAA established a non-deliberative process, at least as far as public input was concerned. Sweco Pic and ITS Global were made exclusively responsible for advising the Government on whether the mill's specifications contained in Gunns IIS and Supplementary Information met the RPDC's Guidelines and on whether the project would have net economic and social benefits. Because both were private consultancies, we know nothing of the debates that occurred within Sweco Pic and ITS Global about the data before them, or between either of these companies and Government over drafts of their reports. Clearly, whatever deliberation occurred under the PMAA took place between a small group of technical elite with a narrow mandate and a foreshortened timeline.

\section{Efficient Decision Making}

Decision making takes time and, all things being equal, the shorter the time the more efficient the decision making process. Various factors mitigate against decisions being taken quickly, however. Key factors of importance in public environmental decision making are (a) the number of parties involved; (b) the amount of information to be assessed; and (c) the seriousness of the risk of getting it wrong. In the current case, it is evident that numerous parties were involved, there was a huge volume of information, and the risks of making the wrong decision were potentially lifethreatening. Hence, it is perfectly understandable that a decision could not be made instantly by the proponent without any consultation whatsoever, which it might do if it were merely a 'private' organisational matter. Hence, an efficient decision in the current context is one that takes time but does not extend indefinitely into the future. Gunns argued that the RPDC process ultimately failed because it extended the decision making timeline beyond the company's 'commercially acceptable' horizon. In its pure form, this is a difficult argument to sustain because it could justify taking a massive investment decision within a very short time period if that was what a company deemed 'commercially acceptable'. On the other hand, it is also true that the RPDC Panel Chair, Christopher Wright, was unable to provide Gunns with a definitive answer as to when a decision might be expected, although he did intimate that it would not be before November 2007 and possibly not until early $2008 .^{29}$ 
Let us assume that it was the later date (i.e. March 2008) when the RPDC's final decision was made (had the process been allowed to continue). Further, let us assume that the RPDC process commenced at the earliest date possible, November 2004, with the establishment of the Pulp Mill Assessment Panel. In that case, the total time to decision would have been three years and five months. Clearly, this is a long time, but is it 'too long'? Comparisons can be invidious, but also illustrative. Thus, for example, the UK Government notes that it took seven years from date of application to approval for Heathrow's Terminal 5; six years and five months to approve the NorthYorkshire electricity grid upgrade; and more than three-years to approve a container port upgrade at Dibden Bay, Southhampton. In this context, therefore, three years and five months does not look particularly long, but of course there are several examples of shorter approval processes in the UK, including Coventry Airport and Felixstowe Harbour, which both took just over a year (UK Government 2007). ${ }^{30}$

Can the potential lengthiness of the RPDC process be justified in terms of the project's complexity and importance and in terms of public interest in the outcome? As all commentators have noted, the proposed Long Reach pulp mill was the single largest proposed investment ever in Tasmania, with major ramifications for the State's economy, ecology and society. Numerous interests were mobilised to propose and oppose the proposal, including not only members of the forestry and environment lobbies, but other actors including those engaged in agriculture, fisheries, tourism and the medical profession. Given the high level of public interest, it would seem reasonable to expect the assessment process to be somewhat lengthy. It is also notable that the total time to completion of the review would have been significantly foreshortened had the Government's Pulp Mill Task Force not interfered with the RPDC's operations and if the proponent, Gunns Limited, had submitted the required supplementary information in a more timely manner. If these two factors were not in play, there is every possibility that the RPDC could have produced a decision by June 2007, meeting Gunns' timeline and reducing the total time to completion to less than three years.

\section{Science-Based Decision Making}

Science plays a major role in good environmental governance, primarily because we rely on a wide range of sciences to understand the effects of human-nature interactions. Unfortunately for decision makers, scientists can disagree on the nature of cause-effect relationships, as well as about the relative priority to be given to economic, social and environmental factors. Such disagreement is ubiquitous in situations where there are multiple variables interacting in complex and chaotic ways. Thus, while science is key, it is rarely definitive: science requires translation in a policy context to make it meaningful (see Haller and Gerrie 2007). ${ }^{31}$

How scientific was the RPDC process? We can note that scientists contracted by Gunns played an important role in the preparation of the company's IIS; that BECA Amec was contracted by the RPDC to review the technical dimensions of the IIS; and that various groups and individuals enlisted science in their submissions to the RPDC process, in some cases challenging the methodology, models and data of other scientists. In short, the RPDC process was awash with scientific arguments over such matters as the composition of the proposed mill's effluent and its potential for bioaccumulation in fish, the structure and operation of the Launceston air shed, the volume and impact of particulate emissions of different sizes on human health, the 
projected increase in road traffic and the adequacy of the road system, and the net economic impact of the project.

To make sense of the diversity of scientific arguments, RPDC employed a large number of consultancies to advise it. These included BECA Amec to undertake a peer review of Gunns' proposal; CSIRO Marine \& Atmospheric Research to review the air quality aspects; Farley Consulting Group to assess the social and community impacts; URS Forestry to assess the wood flow assumptions; and UniQuest to assess the toxicological effects. The questions raised in these consultant reports resulted in the RPDC requesting extensive supplementary information from Gunns Limited.

The science-rich nature of the RPDC's process contrasted rather starkly with the PMAA's, which replaced the public debate over the scientific merits of the mill with two government-appointed consultants with very narrow terms of reference. Sweco Pic was asked to arbitrate on whether the emissions from the pulp mill met the RPDC Guidelines - questions related to transportation, wood supply, tourism and agriculture were removed from consideration. ITS Global's mandate was even more skewed: they were asked to assess the project's social and economic benefits while ignoring the costs. Both consultancies were based on documentation previously collected, which the RPDC already viewed as seriously deficient.

\section{Risk-Based Decision Making}

All projects carry risks related to flawed models of causality, poor data and inexperience in implementation. A project of the magnitude of the Gunns proposed pulp mill and its location in the Tamar Valley is, prima facie, replete with risks. These include economic risks associated with changing market conditions and the potential loss of 'new investment' in viticulture, organic agriculture, information technology, tourism and fisheries; environmental risks associated with air emissions and effluent from the pulp mill, which could bio-accumulate in fish and pollute the waters down Tasmania's East Coast; health risks from particulate pollution of the Launceston air shed; and social risks associated with boom and bust commodity cycles, and the possibility that the mill will require subsidies to protect the jobs created. In such a context, good governance requires that the claims made by proponents are subjected to a robust assessment of the projects costs, benefits and risks. Under the RPDC, this was partially but not completely done. Under the PMAA, risk analysis has been replaced with assumptions of 'fact'.

To illustrate the inherent risks involved in a project of such magnitude, it is instructive to examine the projected benefits of the mill as calculated by Allen Consulting using Monash University's Centre of Policy Studies MMRF-Green model. In the consultant's report to Gunns, a sophisticated analysis of the mill's future economic benefits is provided, estimated to be $\$ 6.7$ billion over a 23-year projection period to 2030, averaging around \$290 million per annum (Allen Consulting Group 2006). These are impressively big numbers and if realised would constitute an important economic rationale for the mill's construction. But all economic models are built on assumptions about the future and there are always substantial risks that those assumptions are wrong. Hence, when presenting the results of economic models, it is normal practice for economists to undertake sensitivity analysis - a point made in Naomi Edwards' detailed review of Allen Consulting's Report in her submission to the RPDC (Edwards 2006). Several assumptions made in the Allen Report to generate 
the 'one big number' of $\$ 6.7$ billion needed to be subjected to a sensitivity analysis, including the key parameter used to discount the value of future earnings, the net present value, or NPV. The purpose of a sensitivity analysis is to indicate the range of project benefits that might eventuate if the model's basic assumptions deviate from those predicted.

There were other risks associated with the MMRF-Green model that might have been scrutinised. One is that the model uses a 'deviation from base-case' scenario, explicitly assuming that the pulp mill investment imposes no costs on others in the Tamar Valley or elsewhere. Given existing 'new economy' opposition to the development in the region as represented by Investors for the Future of Tasmania, this was clearly a heroic assumption that required an explicit defence. This points to a major deficiency of MMRF-Green model: it is not a full cost-benefit model that includes the costs of the economic, social and environmental externalities the project will impose on other actors. While extremely capable at predicting the potential benefits from an investment as expenditures flow through the state and wider economy, models such as MMRF-Green need to be complemented by a cost-benefit analyses to determine if the trade offs that inevitably occur ${ }^{32}$ - between the pulp mill and a possible decline in tourism, fisheries, viticulture and agricultural investment; on the economic costs of pollution of the water, earth and air; and of the health costs in increased lung disease in Launceston as a consequence of increased particulate emissions in the regions air shed; and fatalities from increased logging trucks - are justified. It is perfectly possible that, following such a cost benefit analysis, the project will still demonstrate a net benefit, at which point the public can have far greater confidence in its proceeding.

\section{Summary}

Table 1 compares the RPDC and PMAA processes across all eight criteria of good environmental governance.

\section{Table 1: Good Environmental Governance: RPDC and PMAA Compared}

\begin{tabular}{|l|l|l|l|l|l|l|l|l|l|}
\hline $\begin{array}{l}\text { Proc- } \\
\text { ess }\end{array}$ & $\begin{array}{l}\text { Trans- } \\
\text { parency }\end{array}$ & \multicolumn{2}{|c|}{$\begin{array}{c}\text { Account- } \\
\text { Ability }\end{array}$} & $\begin{array}{l}\text { Open- } \\
\text { ness }\end{array}$ & Balance & $\begin{array}{l}\text { Deliber- } \\
\text { ative }\end{array}$ & $\begin{array}{l}\text { Effic- } \\
\text { ient }\end{array}$ & Science & Risk \\
\cline { 2 - 9 } & & $\begin{array}{l}\text { (Verti- } \\
\text { cal) }\end{array}$ & $\begin{array}{l}\text { (Horiz- } \\
\text { ontal) }\end{array}$ & & & & & & \\
\hline Ideal & High & High & High & High & High & High & High & High & High \\
\hline RPDC & Medium & High & Medium & Medium & Medium & Medium & Low & Medium & Medium \\
\hline PMAA & Low & High & Low & Low & Low & Low & High & Medium & Low \\
\hline
\end{tabular}

As can be seen, the RPDC process falls well short of the ideal, which would be high across all eight criteria. However, it scores well in comparison to the PMAA, which scores high only on the criterion of efficiency, and low on a large number of other criteria including transparency, horizontal accountability, openness, balance, deliberation and risk.

\section{Conclusion}

In a recent book entitled Why Politics Matters, Gerry Stoker of the University of Manchester reflects on why so many people appear to loathe politics (2007, xi). In his analysis, Stoker argues that the major reason is that people misunderstand the nature of democracy and expect too much from it. Politics, he says, 'is designed to 
disappoint', because 'its outcomes are often messy, ambiguous and never final', involving 'the hardest of human skills: listening carefully to the opinions of others and their expressions of their interests' (Ibid., 10). But while Stoker comes dangerously close to blaming the victim in viewing the current citizenry as 'incompetent amateurs' when it comes to politics, his prescriptions for solving the malaise that plagues modern democracy is spot on. He argues in favour of expanding 'the opportunities for citizens to have a say about the issues that they care about' adding that 'representative politics needs to be understood as a more active exchange between citizen and representative and restructured to give more scope for local and global decision making' (Ibid., 15). Indeed, he warns that: 'making the democratic form of governance that now dominates the world work better is the only way we can avoid something worse taking its place....' (Ibid.).

The Tasmanian case study illustrates how serious the obstacles are to realising Stoker's 'new governance' objectives. Despite an adversarial approach, technocratic belief system and a certain elitism, the RPDC's approach to assessing the pulp mill met the minimum requirements of good environmental governance. It provided a basic level of transparency, accountability, openness, balance, deliberation, science and risk. Its capacity to function efficiently was hampered as much by external factors-government interference via the Pulp Mill Task Force and Gunns inability to meet its own deadlines - as by its internal decision making arrangements. Yet, when this relatively modest approach to institutionalising good environmental governance appeared unlikely to deliver the 'right' decision, Tasmania's forest lobby had no compunction in jettisoning it in favour of a fast-track alternative under the PMAA. When a state's planning laws can be so easily gutted when they fail to deliver what powerful groups want, communities confront a stark choice between 'good' and 'bad' the relative weakness of legislative solutions to the establishment of even stronger, constitutional, protections will be required to prevent

Tasmanians, however, are rising to this task. While experiencing an almost complete breakdown in their political system due to the power of the forest lobby and the complicity of the political establishment, they have responded by seizing every opportunity to make their views known. These have included participating in anti-mill demonstrations, establishing an anti-pulp mill electoral role to contest local council and commonwealth elections, and making submissions to the mill's most likely financiers, ANZ Banking Group Limited (ANZ). While each of these actions has been successful in its own terms, with tens of thousands of Tasmanians taking to the streets, ${ }^{33}$ the Mayor of Launceston dumped out of office, ${ }^{34}$ the premier Paul Lennon resigning, ${ }^{35}$ and ANZ announcing it would not fund the pulp mill, ${ }^{36}$ citizens continue to live under the shadow of the pulp mill's possible construction. ${ }^{37}$ 


\title{
End Notes
}

\begin{abstract}
${ }^{1}$ The Guidelines were developed with significant input from Dr. Warwick Raverty, a CSIRO pulp mill specialist, who was later to play a key role in the drama (see below).

${ }^{2}$ The consultant was Robert Eastment of the Hobart-based consultancy, IndustryEdge.

${ }^{3}$ The warning was repeated again in early 2007, when it was reported that the company was in preliminary talks with the Mayor of Glenelg Shire, Victoria. It is hard to gauge how seriously the company regarded these statements or whether they were merely a form of 'sabre-rattling' designed to strengthen the hand of politicians with respect to an increasingly sceptical Tasmanian public. The cost implications of building a mill elsewhere, however, could be expected to be significant.

${ }^{4}$ For a detailed account of the 2006 Tasmanian election, see Scott Bennett, 'Understanding state elections: South Australia and Tasmania 2006’, Department of Parliamentary Service Research Brief 17 2005-06 (19 May 2006), online at: http://wopared.parl.net/Library/pubs/rb/2005-06/06rb17.pdf,
\end{abstract} accessed May 2008.

${ }^{5}$ The report was from the Commonwealth Banks financial analysis arms, CommSec. In the same news item, Robert Eastment is quoted as observing that the CommSec report was only one among many and other analysts were not nearly as negative.

${ }^{6}$ Data comes from FinAnalysis data base. The monthly closing values for Gunns shares for 2006 are given as: 30/11/2006 (2.91), 31/10/2006 (2.90), 29/09/2006 (2.56), 31/08/2006 (2.76), 31/07/2006 (2.60), 30/06/2006 (2.81), 31/05/2006 (2.98), 28/04/2006 (3.18), 31/03/2006 (3.30), 28/02/2006 (2.90), 31/01/2006 (2.86). FinAnalysis, AspectHuntley, www.aspecthuntley.com.au, accessed May 2008.

${ }^{7}$ Raverty's notes on the affair, quoted at length in the Tasmanian Parliament, state: "On 20 December 2006, Julian Green said to me, '[Solicitor-General] Bill Bale says if you choose to stay and fight this allegation of 'apprehended bias' in the Supreme Court, the Commission will have to seek my [Bill's] advice on whether they should pay your costs. He would have to advise the RPDC that because of the decision in the High Court in the case of Ebner, supporting Raverty would be far too risky. It would cost hundreds of thousands of dollars and you would almost certainly lose. In addition, the case would delay the mill review by up to 2 years. I would have to advise the Commission that the only practical course is for it to withdraw Raverty's delegation.' Indeed, Green's justification for his own resignation was that: "He [Premier Lennon] promised me on 2 February that the Task Force would not contact CSIRO. Look here is my diary entry for that day "Meeting with Lennon ....... advised Premier concerns re Raverty. Told Lennon TF not to contact CSIRO or Ensis under any circs. Premier said, "consider it fixed, Julian". Good meeting!...'A month later that idiot Bob Gordon signs a contract with Ensis to do a review of bleached pine effluent toxicity. I am really totally pissed off with Lennon. I will have to resign from the panel myself, Bill told me that. And I'm damn well considering resigning from the RPDC' (Booth 2007).

${ }^{8}$ Warwick Raverty, the CSIRO pulp mill expert, immediately began to speak out after his resignation. Among other comments, he is reported to have stated that the mill was being proposed for the 'worst site possible in Tasmania' (Neales 2007a).

${ }^{9}$ Importantly, however, the majority of this amount $\mathbf{( \$ 8 0 0 , 0 0 0 )}$ derived from 'lost earnings' and was not actual expenditure. Current expenditure related to the delay appear to have been about $\$ 200,000$ per day or $\$ 6$ million a month.

${ }^{10}$ Wright noted further that: 'This [delay] was obvious well before the October Directions Hearing last year and I think should come as no surprise to interested parties, least of all the proponent. A subsequent time line has now been prepared which details the remaining steps which need to be followed before this assessment process can be completed. An approximate, and I think very optimistic, completion date has now been forecast for late November of this year (Wright 2007: 3).

${ }^{11}$ Data comes from FinAnalysis, AspectHuntley, www.aspecthuntley.com.au, accessed May 2008.

${ }^{12}$ Although the details are obscure, TAP emerged in June 2006 following internal disagreements within the Tamar Residents Action Committee (TRAC) over that organisation's strategy and tactics. TAP is now a major vehicle for local community dissent concerning the pulp mill. See http://tapvision.info/node/82 for further details.

${ }^{13}$ Gunns ran a series of half-page advertisements in both the Mercury and Examiner throughout the first half of 2007 based on the theme of explaining the 'facts' about the pulp mill. The Government committed $\$ 300,000$ to a publicity campaign designed to 'sell' the two consultants reports conducted under the Pulp Mill Assessment Act 2007 by Sweco Pic and ITS Global. This was in addition to funding for the Pulp Mill Task Force, which ran its own pro-pulp mill publicity campaign over a twoyear period from early 2005 to late 2006. Other 'new economy’ action against Gunns pulp mill included a mainland sommelier and restaurant boycott of wines from Gunn's-owned wineries (Port 2007). 
${ }^{14}$ The author of this paper was a signatory of the letter.

${ }^{15}$ Following the publishing of the report on the Legana Assembly of God's website, Corbett was immediately contacted by Rene Hidding, Liberal Member of the House of Assembly for Lyons, who set up a meeting between Corbett and Les Baker, Gunns pulp mill project manager. This meeting led to a revised version of the article. Subsequently, Corbett had detailed conversations with Greg Stanford, Gunns’ Infrastructure Manager and a ‘committed Christian and member of St Aidan’s Anglican Church'. A report of the meeting follows on the web site in the form of a series of questions posed by Corbett and answers given by Stanford.

${ }^{16}$ Under Tasmania's bicameral system, the Bill was then referred to the upper house, the Legislative Council. Unlike many other elected upper houses, Tasmania's is not dominated by political parties and contains a majority of 'independent' members. In a political oddity, Tasmania's Upper House sits permanently and is never formally dissolved. Instead, elections are held annually for three or four seats according to a permanent electoral cycle. In May 2007, for example, elections were held for the three seats of Montgomery, Nelson and Pembroke, with all three returning incumbents.

${ }^{17}$ Of the MLCs opposing the bill, the most damaging to the Government was ALP party member Terry Martin. In a major speech to the House, Martin stated that although he was in favour of a pulp mill in Tasmania, he could not support the process set out in the bill. Martin took special aim at his leader, Paul Lennon, and the 'cargo-cult' mentality he and members of the forest lobby were promoting, and rejected their central argument that a failure to pass the bill would return Tasmania to the dark economic days of the past. He noted that Tasmanians had been told in the 1970s that 'the skies would fall in if we did not build a dam; in the 1980s the sky was going to fall in if we did not build a pulp mill at Wesley Vale. In the 1990s the sky was going to fall in if we did not sell the Hydro. Well, none of these things happened and the sky did not fall in - the doomsayers simply were wrong' (Martin 2007). In outlining his objections, Martin endorsed the views of many in the community, especially those who argued that the approval process was as important as the outcome and that Tasmanians had as much right to expect that the State's planning arrangements were respected as Gunns did of having a decision made within a commercially viable timeline. Martin ended his speech with the following quote from Martin Luther King: 'On some positions, cowards ask the question, is it safe? Expediency asks the question, is it Politic and vanity asks the question, is it popular? But conscience asks the question, is it right? And there comes a time when one must take a position that is neither safe, nor politic, nor popular, but he must do it because conscience tells him it is right' (Martin 2007).

${ }_{18}^{18}$ In addition to Terry Martin (Elwick), Norma Jamieson (Mersey), Sue Smith (Montgomery), Jim Wilkinson (Nelson) and Kerry Finch (Rosevears) all voted against the PMAA.

${ }^{19}$ The President of the Legislative Council votes only in the event of a tie.

${ }^{20}$ These were the original generic guidelines proposed by the RPDC in November 2004, not the finalscope guidelines that the Commission had developed specifically for the Long Reach site in December 2005.

${ }^{21}$ Sometimes, however, a lack of knowledge stands in the way. This occurred when chlorofluorocarbons were first invented in the 1930s. Viewed at the time as inert, with excellent refrigerant properties, neither the scientific theory of their interaction with the ozone layer nor any evidence of such an effect existed. But even when good quality information exists, it may be deliberately kept secret. Tobacco companies have limited damage to their 'industry' by blocking the release of studies that demonstrate a causal relationship between smoking and lung cancer and by deliberately conducting and promoting studies that cast doubt on any such link.

${ }^{22}$ Pillar observes: 'In the upside-down relationship between intelligence and policy that prevailed in the case of Iraq, the administration selected pieces of raw intelligence to use in its public case for war, leaving the intelligence community to register varying degrees of private protest when such use started to go beyond what analysts deemed credible or reasonable. The best-known example was the assertion by President George W. Bush in his 2003 State of the Union address that Iraq was purchasing uranium ore in Africa. U.S. intelligence analysts had questioned the credibility of the report making this claim, had kept it out of their own unclassified products, and had advised the White House not to use it publicly. But the administration put the claim into the speech anyway, referring to it as information from British sources in order to make the point without explicitly vouching for the intelligence' (Pillar 2006, n.p.).

${ }^{23}$ Barrados notes in her speech that Canada's Auditor-General's Office has backed away from this narrow conception of accountability, now defining it as "a relationship based on obligations to demonstrate, review, and take responsibility for performance, both the results achieved in light of agreed expectations and the means used.” 
${ }^{24}$ For an extended discussion of the etymology and analysis of the concept of accountability, see Bovens (2006). Bovens actually identifies three forms of accountability: vertical based 'on the delegation of principles to agents'; horizontal, which is 'moral in nature' and 'not based on legal requirements'; and diagonal, which is 'accountabilty in the shadow of hierarchy' (2006, 21).

${ }^{25}$ As a broad generalisation, the Tasmanian Resource Management and Planning System (RMPS) established in 1994 conforms to best practice in that it permits widespread public involvement in the planning process without limiting involvement, with the singular exception of the forest management planning. Hall (2002, n.p.) makes this point when he notes: "From the perspective of public participation, the key element of this [RPMS] process is the fact that a person does not need to demonstrate any proprietary or material interest in a particular development in order to be able to appeal against it. LUPAA [Land Use Planning and Approvals Act 1993] thus provides the whole community with open standing to formally challenge developments, not just on legal technicalities, but on merit according to broad ecologically sustainable development criteria. It allows people who do not have wealth and property to have a say in how others (who have it) can use their land and natural resources. It is democracy in action but it turns the notion of private land ownership on its head and the RMPS has not gone without its share of criticism, particularly from the business sector.” The RPDC is a central component of Tasmania's RPMS and is constituted as an 'independent' body and its commissioners are expected to impartially assess projects based on technical expertise and reason. However, the 'independence' of the RPDC is qualitatively different from that of some other independent bodies, notably central banks. The latter are explicitly set up to isolate decision making from public scrutiny and public input.

${ }^{26}$ This was particularly the case when the Premier made an emergency trip to Launceston on 12 January to discuss Gunns threat to pull out of the RPDC process on foot of the resignations of Raverty and Green (Neales, 2007i).

${ }^{27}$ In Australia, there are fewer policy networks more closed than the Tasmanian forestry sector. Despite his tendency to excoriate everything and everyone, Mark Latham's account of how this network operated in the run-up to the 2004 Federal Election appears to capture much of its essence. According to Latham, 'The problem with the Forestry Division [of the CFMEU] is that is has formed a dependency relationship with the companies. Their officials can't fart unless the bosses say it's okay" (Latham 2005, 352).

${ }^{28}$ The PMAA process was fully backed by the forest lobby despite early endorsements of the RPDC process. The CFMEU, for example, published a full page advertisement in the Hobart Mercury under the headline 'The Tasmanian people have already voted for the pulp mill.' Ironically, it was the CFMEU, locked in battle over the Federal Government's WorkChoices legislation that it regarded as egregiously unfair, that defended the narrowest conception of the Tasmanian government's policy mandate. The advertisement reprinted a speech by John Sutton, who argued that because Tasmanian's had voted in Paul Lennon in early 2006, they had also voted for the pulp mill. By a similar logic, since Australians had voted for John Howard in the 2004 election, they were similarly committed to WorkChoices, a position Sutton and the rest of the union movement would never endorse. In addition to the CFMEU, advertisements were published in favour of the PMAA by the Forest Industries Association of Tasmania and Timber Communities Australia. The Tasmanian Chamber of Commerce and Industry (TCCI) sent a delegation to Canberra to plead the case to Minister Turnbull in an effort to secure the mill's approval before the government went into caretaker mode (Tasmanian Business 2007). ${ }^{29}$ See endnote 10.

${ }^{30}$ Notably the British White Paper recommends expanding the opportunities for public involvement in the planning of major infrastructure projects.

${ }^{31}$ In an extended discussion, Haller and Gerrie (2007) cover many of these issues. Intriguingly, they argue against the adoption of environmental assessment procedures because the underlying, two-stage model of science on which it is based — scientists discover the facts and politicans make decisions - is seriously flawed. Building on a distinction between 'curiosity-driven science', which is open ended, and 'mandated science', which is forced to render a decision based on what it known at a particular point in time, the authors argue for "a better model for the involvement of scientists in public policy debates is that of being participants in particular interest groups ("hired guns"), rather than as supposedly unbiased consultants to decisionmakers” $(2007,139)$.

32 This point is made clearly by Bruce Layman of Western Australia's Department of Treasury and Finance. In his conclusion, Layman states: "The key challenge ahead is for governments is to require that project proponents, and consultants that they employ, to provide the data required to fully analyse the costs and benefits of the request for assistant (sic) in question. This will be difficult as the current 
method of splashing large numbers regarding production, consumption and employment into submissions and the media is to the benefit of project proponents seeking the subsidy. However, unlike at least some requests for project assistance, the benefits of undertaking this action should well and truly exceed its costs” (Layman, n.d).

${ }_{33} 10,000$ people marched through the city of Launceston in June 2007 to demonstrate their opposition (ABC News 2007h) and a second anti-mill rally in Hobart on 17 November 2007 attracted an even larger number (Stedman 2007a). These rallies were countered by a smaller, pro-pulp mill demonstration of about 5,000 in July, although it should be noted, though this rally was paid for by the forest industry, with workers given the day off and bussed in from across the state (ABC News 2007c; Hobart Mercury 2007b ).

${ }^{34}$ TAP claimed to have 16,000 Tasmanians registered in a voters' block to vote against pro-pulp mill politicians and it appears to have played a role in defeating the incumbent Mayor of Launceston, Ivan Dean in the October 2007 local council elections (Denholm 2007b).

${ }^{35}$ Premier Lennon resigned in late May 2008, following a devastating poll that showed his personal approval rating at a record low of $17 \%$ (Darby 2008b).

${ }^{36}$ ANZ released a 5-line press release in May 2008 stating that the company "will not be participating in the provision of finance for Gunns Limited's proposed Bell Bay Pulp Mill in Tasmania" but refusing to provide any reasons due to 'client confidentiality' (ANZ 2008).

${ }^{37}$ Should the proponents obtain financing and proceed, there is every likelihood of further conflict. At a rally in Hobart in November, Richard Flanagan asked demonstrators to indicate by a show of hands whether they were prepared to block the mill's construction. Almost 10,000 hands went up into the air (Flanagan 2007). If construction is attempted, it will be hard to avoid a repeat of the mass arrests that occurred during the Franklin Dam blockade of 1982/83 (see Hay 1994; Doyle and Kellow 1995; Crowley 1999). 